\title{
THE PROTEAN NATURE OF LANDSCAPES IN JOHN BARTH'S LOST IN THE FUNHOUSE
}

\begin{abstract}
This paper analyzes John Barth's Lost in the Funhouse from the particular perspective of the status of spaces in an attempt to show how landscapes tie in with Barth's attitudes towards storytelling and how the shifting nature of those landscapes becomes the object of focus. Examined in the paper is the connection between the protagonists' identities and the landscapes. Alterations including the landscapes are simultaneously part of what is referred to here as the protean nature of space and a challenge to any passivized approaches to a text. Two levels of comparison are applied in order to achieve this goal: Barth's theoretical essays - primarily "The Literature of Exhaustion" and "The Literature of Replenishment" - are examined in relation to the collection of short stories whereas narrative strategies concerning landscapes are compared to those which primarily deal with protagonists and plots. When everything else fades, be it atypical narrators, heroes and eventually even audiences, only art and experience endure - or more precisely - storytelling and love.
\end{abstract}

Key words: identity, direction, John Barth, otherness, labyrinth

John Barth's The Literature of Exhaustion and Lost in the Funhouse were published one year apart and therefore many of the essays' issues are to be found within the pages of the fourteen stories as the literary continuation of the author's theories. Experts like Christopher Butler astutely describe such proximity as "the alliance between art and theory" and as "one of the most obvious symptoms of postmodernist influence" (2002: 76). Not only is theory interconnected with fiction, but the form of that fiction is not always easy to outline: in his study Death in the Funhouse: John Barth and Poststructuralist Aesthetics, Alan Lindsay classifies Lost in the Funhouse both as one of Barth's novels and as a collection of short stories that is essentially about how "we are writing a book about ourselves writing a book" (Lindsay 1995: 2, 3), whereas E. Walkiewicz (1986: 125) finds it both experimental and traditional. In these two works, Barth primarily disputes narrative conventions concerning plots, themes,

\footnotetext{
“Faculty of Philology, University of Belgrade, Studentski trg 3, 11000 Belgrade, Serbia; e-mail: milosars@ mts.rs
} 
and protagonists, so his treatment of landscapes provides synonymous perspectives, one theoretical and the other literary:

Because of Barth's aesthetic stance and epistemology, any particular venue $[\ldots]$ is presented as a partial picture of a protean world seen from a particular point of view, a reflexion of a necessarily distorted reflexion of things as they may be or might have been. (Walkiewicz 1986: 4)

The Literature of Replenishment confirms what a good reader might have already discerned from Barth's fiction, that there is more to it than simple antithesis to convention, that the contraries of linearity, rationality, consciousness, cause and effect, transparent language and middle-class moral conventions are not the whole story and that disjunction, simultaneity, irrationalism, anti-illusionism, self-reflexiveness, medium-as-message and a moral pluralism approaching moral entropy are equally insufficient as their counterparts (Barth 1984: 203). Postmodernism heralded alternative approaches to storytelling whose form changed accordingly. Once mimetic narration had been disposed of, writing focused more on fictionalizing and transformation. The premise being established is that if the title story is the frame-tale of the collection, then the labyrinth of that same story is both the frame-narrative and, more importantly, the frame-landscape. Since Barth (1984: 66) claims that the literary equivalent of Chartres Cathedral is not feasible in our time, the autonomous and impersonal labyrinthine structures of Lost in the Funhouse are its adequate replacement and a spatial counterpart to the temporal disorder of postmodernist fiction. In other words, the questions posed relate to what lies beneath these spatial anagrams and what could the position of the landscapes within Barth's restructuring of narrative strategies be.

Let's start with a brief outline of the significance Barth attributes to the other participants in storytelling. According to A. Lindsay, Barth reveals the author "as a function of the text rather than the text as a product of the author" (1995: 74). This is not "the Aristotelian conscious agent [...] endowed with uncommon talent [...] who achieves with technique and cunning the artistic effect" (Barth 1984: 65). Equally atypical is the hero. Walkiewicz (1986: 110) defines Barth's heroes as artists, practitioners of the art of heroism and the vertiginously enigmatic landscapes of Lost in the Funhouse present more of a challenge precisely because mythical monsters are conspicuously omitted. When the author is devoid of authority and the hero is less of a protagonist and more of a function, then the landscapes are approached functionally as well, with no decorations and no conventional virtuosity. In fiction described by Barth as "a kind of true representation of the distortion we all make of life" (Prince 1968: 54), the end of the reader's passivized appreciation for the text is marked by various 
permutations to which the protagonists and narrators are subjected, which leaves one wondering about the nature of these permutations regarding spaces.

The lack of the predetermined identity of the hero is unmistakable, at first indicated by his frequent namelessness. Incidentally, Barth (1984: 74) reminds us that some heroes conceal their identities intentionally, such as for example Menelaus, who disguises himself in order to ambush Proteus. The identity of various protagonists remains rudimentary: one is a sperm, another is an echo, and one's last name is Mensch - perhaps to be read as John Doe, Everyman. Namelessness persists throughout the collection, all the way to the final story, appropriately titled Anonymiad. Echo and Narcissus also have identity issues: the former with auditory and the latter with visual reflections of the self. These are all shadows of identities. Ambrose is not baptised, i.e. the ritual of assigning a name is repeatedly put off until he is thirteen, his mother keeps calling him Christine, after Anna Christie, from the cinematic adaptation of Eugene O'Neill's play of the same name starring Greta Garbo, another tale of hidden histories and indistinguishable identities shrouded by sea and fog. The conventional grandiosity of the mythical hero is further deflated by the unclear circumstances of his birth: Ambrose does not know who his father is and candidates are aplenty. The threat of a father figure - frequently found in mythology - in this case, is replaced by a paternity dispute. Hector keeps suspecting that the boy might have been fathered by someone else until the suspicion drives him mad and he ends up in an institution which - as a variation of space - perfectly corresponds to the condition of his mind. Closeness to nature is yet another traditional feature of the mythical hero. This is relevant because Tom, Ambrose's grandfather and possible father, is a hedonistic artist surrounded by nature, a complete opposite to Erdmann.

Another prominent aspect of this revision of identity found at the forefront of the collection is fictitiousness, primarily that of the protagonists, some of whom are beginning to suspect that they might not be real and are striving to reverse the process. In various ways, even corporeality is denied to the narrator of Anonymiad, to Echo, and to the correspondent in Petition who is both nameless and attached to his Siamese twin. Surprisingly enough, the reader also seems to be threatened by fictitiousness, proportionally to the teller who is immaterial (Barth 1988: 101). It would appear that individual identities are seldom allowed, including that of the author, who is also not spared the recurrent fictitiousness: "He had [...] mentioned to no one his growing conviction that he was a fictional character [...] the possibility would occur to the writer of these lines that his own life might be a fiction, in which he was the leading or an accessory character" (Barth 1988: 120,116). Fictitiousness is equally underlined through absence in the sense that ultimately, the very presence of everyone is in question both indirectly - "for all one knows the speaker may be the only auditor" - 
but also directly: "the medium of his life was prose fiction" (Barth 1988: 102, 120). The assumption I entertain here is that through fictitiousness Barth actually indicates the ephemerality of everything apart from art and experience, or more precisely the eternity of oral storytelling and the emotion of love.

Let's take a look at how the complex recesses of Barth's deepest labyrinths reflect the above-mentioned revision of identity. The new world stands next to the ocean beyond which the old one lies. Ambrose's family members are of German descent and use their native language alternatively with English as a sort of connection to that old world. Not so different from Maryland in another of Barth's novels, this territory is newly acquired and is still influenced by the homeworld and its heritage. In the title story, the ocean is marked as dangerous otherness, "a place of fear and confusion" (Barth 1988: 72), where war rages on and U-boats threaten. Ocean City, however, is a place of love, where "almost all the people on the boardwalk were paired off into couples except the small children" (Barth 1988: 89). Just like any other mythological hero, Ambrose lives near large bodies of otherness, the ocean being one of them, and visits a city named after that otherness, where two worlds meet. Although he goes to the seashore on Independence Day - a hint of his coming of age - like any typical hero Ambrose still needs to overcome a prior lack of courage by conquering an equally mythical but infinitely more complex expanse, this time a labyrinth instead of a perilous rock and a whirlpool: "Just past the alley [...] was a place he had named Scylla and Charybdis [...] a Spitz dog [...] snarled from his house and flung himself at any passing kid [...] the yard of crazy Alice" (Barth 1988: 41). In other words, young Ambrose is caught between a rock and a hard place. Here is a glimpse of additional otherness preceding the labyrinth of the funhouse, a reflection of Ambrose's childhood, his former self: "The Jungle [...] stood atop the riverbank between the Nurses' Home and the new bridge $[\ldots]$ bounded by [...] Erdmann's corn lot [...] and by the [...] dump" (Barth 1988: 48). The neighborhood is also haunted by the Arnie twins: "pale as two ghosts they shuffled through the alleys [...] poking in people's trash cans [...] unwashed, unbarbered" (Barth 1988: 41). The old otherness is then replaced by a labyrinth, the very structure the hero is supposed to escape if he wants to return home. It is obvious that Ambrose does not feel safe or comfortable in this surrounding and daydreams about "Bangkok or Bozcaada" (Barth 1988: 42), an exotic landscape which still symbolizes otherness. It may be that another story, Petition, also takes place in Bangkok, in a way. The dog and the twins seem to be childhood equivalents to monsters that are made obsolete prior to entering a more complex otherness of their own making that requires no monsters whatsoever. Still, regardless of their identity problems, not even the most unreliable of narrator lacks either the determination or special predispositions to tell a story. Although he has been called a sissy and a wimp by both his family and school 
friends, Ambrose does not hesitate to strike Perse to get the bottle with the message in it. Both Ambrose's name and the surrounding landscapes announce him not so much as the hero but as the future storyteller. Moreover, three stories - Ambrose His Mark, Water-Message, and Lost in the Funhouse - are all about Ambrose and even their titles hint at the development of a storyteller.

But if there is no monster, and the only prevailing presence is the complexity of a structure, then what is it that landscapes such as these signify? Ambrose gets lost behind a stage, in the works of the funhouse. Like a mythical hero, the reader also descends into the unknown, into labyrinths and other worlds which are an indication of his predicament. The funhouse fits the bill perfectly as a mythical space contrasted to everyday banalities. However intricate, any labyrinth is still less than a piece of machinery, but the funhouse mechanism surpasses that limitation. Note the differences and similarities between the Minotaur's labyrinth and that facing Ambrose: the underage and otherwise scarcely formed and nameless hero enters a complex set of corridors appropriately placed by the sea - "truly a tidewater region where various antinomies tug in opposing directions" (Walkiewicz 1986: 5) - in search of an elusive damsel who has eloped with his elder brother. The mechanical figure at the entrance mocks the hero whose image is distorted by mirrors casting reflections as a metaphor for losing one's way. At the center of this structure there is no monster, but an emotion, which closely resembles the narrative of Menelaus. By the time the stories progress to Menelaus, even the physicality of a labyrinth is no longer required and it is transformed into a narrative profundity with love again at its center, just as it is at the center of the funhouse corridors. While searching for the object of that emotion, Ambrose is in constant danger of going back to where he started or of running in circles, and the love he pursues escapes him. Menelaus shakes down Proteus not to find his way in, but out, to return home because it appears that for Barth at least, finding love and direction are more of a challenge than slaying a monster.

The otherwise unstable identities of Barth's protagonists lost in reflective narratives are partially replenished by loving someone: "when [...] every tale, all tellers, all told [...] in ten or ten thousand years expires, yet I'll survive [...] the absurd, unending possibility of love" (Barth 1988: 156). So storytelling survives along with love as the most important of all themes, to which individual identity is irrelevant: Helen did not choose to marry Menelaus because of who he was, Ambrose is another protagonist who is in love and lacks proper identity, and the sperm from Night-Sea Journey is in love even though it is a preformation, a homunculus. When the narrator of Life-Story admits that he "suspected that the medium and genre in which he worked [...] were moribund if not already dead" (Barth 1988: 121), one may conclude that, while some of the contemporary forms of storytelling can become obsolete and 
eventually exhausted, the storytelling itself - whether in a bottle or in a book - cannot. Accordingly, Barth's stories are not united by plot or tradition, but first and foremost by love as the ultimate experience, as enduring as the art of storytelling. Like Narcissus and Echo, most of the other characters of the "thirst for love" series (Barth 1988: 102) are separated from it in various ways. Not unlike Ambrose, Narcissus needs to learn to pursue more than multiple reflections of himself. Love, in general, is sought for in maze-like structures and it underlines equally complex narratives. It is at the very centre of the narratives in Menelaiad: Menelaus first tells Telemachus about the return from Troy with Helen, then he tells Helen about his encounter with Proteus, to Proteus he tells how he met his daughter Eidothea, but at the centre of all these accounts is

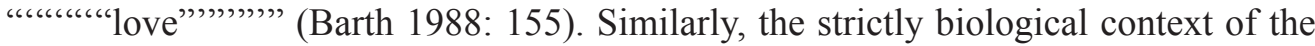
first story is given a different perspective through a reinvigorating parody in which a sperm introduces love to an act of conception. Moreover, there is something archetypal about the object of love, whether it is Her in Night-Sea Journey or Helen, the fairest woman of Menelaiad. This brings us back to the relationship between storytelling as a form of art and love as a manifestation of experience. All the important motifs of Lost in the Funhouse are founded either on love or on storytelling. When he mentioned fiction as performing art, Barth (1984: 63) could have described oral storytelling in the same way. If a novel is regarded as an obsolete storytelling device that cannot stand comparison with oral tradition - because the reader is further away from the source when compared to the listener who is sitting right next to the storyteller Barth's stories are like funhouse mechanisms that alternately open and close the gap between the author and the audience in their own enigmatic manner. Experiences may just be the only reliable part of the fourteen stories. To experience an emotion like love is one thing, and to express it completely another (Lindsay 1995: 121) because experience transcends the expression of it. That is why naming heroes is irrelevant. For E. Walkiewicz, "naming is dependent on an oversimplification of experience", whereas "sufficiency and closure are characteristics not of experience but of art" $(1986: 39,54)$.

Although Barth emphasizes the "used-upness of certain forms or [...] possibilities" (Barth 1984: 64), space does not appear to be his primary preoccupation, like the relativization of logocentrism and the powers of language. Although it is obvious that the experience of art has changed regarding narrators and protagonists and that the same applies to landscapes, the exhaustion of the printed word does not imply that the exhaustion of narrative landscapes is of the same nature. Landscapes are an integral part of the same narrative playfulness recognized in all the stories of this collection and a means of showing identity and all the dilemmas that go with it. They become more important as reflections of the artist's creativity and the identity of individual protagonists than a simple setting for a scene. As early as in the subtitle 
Barth states that some stories are more than just print to be read and should be told in different ways, and this notion equally applies to spaces, or at least it appears to, because when reconstructed, this author's oeuvre resembles an endeavour to construct various paths to the center and then out of a labyrinth. Barth's landscapes are not meant to be narrow and hinder the reader's interpretative capabilities but quite the contrary, to challenge and inspire them and that is why they are as vast as they are complex. Lost in the Funhouse resembles a dimensional variation of the Moebius strip, a kind of literary maze beginning and ending with Once upon a time there was a story that began..., a perplexing loop of one distortion upon another. For Barth, space can be and is the result of both the author and the reader's craft, like that of constructing an "incredibly complex" funhouse in whose "multifarious vastness" (Barth 1988: 97) memories and dreams form landscapes of their own. Just as questioning tradition has to be moored in tradition to at least some extent, so are the landscapes of Barth's works reminiscent of his native Maryland. Arguably, the landscapes of Lost in the Funhouse are largely autobiographical:

... [I]n every one of Barth's books, Maryland serves as either a point of departure or a final destination. Even his ostensibly most self-reflexive creation, Lost in the Funhouse, includes a cluster of stories that contain realistic descriptions of East Dorset and Ocean City. (Walkiewicz 1986: 4)

These postmodern landscapes are as sharply demarcated from the premodern ones as postmodern narrative overlaps with its traditional counterpart. Again, this is not to say that these landscapes are reduced to backdrops. Once the hero steps into the unknown, that unknown might as well appear to him as a labyrinth, an intricate system of corridors, the complete opposite to the mundanity left behind. There is no pretentiousness about Barth's landscapes. It is through the hero's diminishing identity that he is relegated to the background, the foreground being reserved for what was once an obstacle, a complex structure that is a goal unto itself, a symbol of the creative process. The hero, therefore, does not emerge as a monster-slayer, but as labyrinth maker.

The shifting identities of the protagonists correspond to the shifting properties of the text. The uncertainties related to identity issues are not the only ones that make the narrators "heterodoxical" (Barth 1988:36) and the protagonists perpetually atypical and unconventional. Although blind, Tiresias is nevertheless a seer who reveals directions and predicts future events speaking in tongues, but regardless of whether they are protagonists or narrators, "prophets get their tenses mixed" (Barth 1988: 161) until the story becomes "its own medium" (Barth 1988: 102). In "a disengendered tale - none 
can tell teller from told" (Barth 1988: 102). In fact, the teller is just as disengendered as the tale: according to one version of the myth about Tiresias, he stumbled upon the goddess Athena bathing in a lake and she transformed him into a woman for a period of seven years. But there is also another account according to which Tiresias was turned into a woman having chanced upon a pair of mating snakes on Mount Cyllene which he wounded with his stick, an affront to the goddess Hera. Multiple versions of the same story fare well with Barth's playfulness. Similar to Proteus, Tiresias is yet another old man able to change his physical appearance who advises someone - in this case Odysseus - on finding a way home. Tiresias was also involved in the story of Oedipus, which was yet another myth involving the identity crisis of a wayfarer. Ambrose and his brother Peter appear to be different aspects of the same person whose creative and artistic mind could be represented by the younger of the two. Ambrose's nickname Amby reveals ambivalence. Direction is therefore equally concealed in both the narratives and spaces of the fourteen stories. It is not only the protagonists, but also the readers who are lost within the funhouse, so in these ways, the readers share the uncommon traits with the characters as much as they do with the landscapes. In book IV of Homer's Odyssey, while on the island of Pharos, determined to make the mysterious old man tell him the way home, Menelaus seizes Proteus, so the traveler - who has "lost course and steersman" (Barth 1988: 131) somewhere along the way makes an effort which yields information about the right direction. Similarly, by firmly clinging to the continuously shape-shifting landscapes, the reader is welcome to try to obviate the risk of getting lost. The only direction the reader believes truly reliable is left to right, all others being somewhat disorienting. In order to escape the labyrinth, the hero must first venture into its center and face whatever he believes awaits him there. For Barth "the world is a novel [...] astrew with isled souls" (Barth 1988: 117, 196). The narrators are insular, isolated either in a night sea or stranded on an island like the minstrel from Anonymiad or like Ambrose in the funhouse. In Anonymiad, the narrator is a minstrel trapped on a deserted island, "sundried, seasalted [...] My very name lost sense; anon I forgot it" (Barth 1988: 156). There is also a hint of exile in the labyrinthine world of an artist like Ambrose.

The landscapes found within the stories and the strategies behind the storytelling are equally unconventional. Any author aiming to dispute the forms deemed exhausted must also conjure alternative spaces and Barth does just that because the landscapes of the stories are as surprising as their protagonists. Premodernist storytelling imposes the way in which to understand the text and the labyrinth does exactly the opposite. The narrator of Night-Sea Journey is burdened by tradition and quotes passages from literature and philosophy. However, that narrator is a sperm, which does not make the nature of the night sea any less puzzling. Although the setting described in this story 
is not a labyrinth, it is nevertheless just as elaborate and - in the same way as the other stories - it reveals narrative traditions as equally "self-conscious, vertiginously arch, fashionably solipsistic, unoriginal" (Barth 1988: 117). These traditions are - in effect - a type of narrative otherness that the young storyteller needs to overcome.

A sperm is just one of the billions whose survival depends on finding the right direction. It cannot be promoted to the status of the somewhat omniscient, slightly depressed and well-read narrator without betraying at least a trace of parody which turns into a farce when pushed far enough. Moreover, when a sperm is the narrator, the narrator's perspective plays an equal part as the space surrounding it. In combination with common protagonists and language, traditional plot steers the reader in a desired direction, but Barth's storytelling opposes such an approach in all these segments and more, it rejects funhouses "of a superficial kind, in which people only pretend to get lost" (Lindsay 1995: 119). A labyrinth is a place in which one tries to establish a sense of direction, so it is, therefore, no wonder that this structure - the mise-en-abyme and room with mirrors - stands at the center of the funhouse. Both a labyrinth and a Moebius strip end at the beginning and run in circles and "our story's finished before it starts" (Barth 1988: 103). The discontinuity of the series is further emphasized by the fact that it opens ab ovo with the Night-Sea Journey and closes in medias res with the Anonymiad. Ambrose's water message stands at the beginning, and the minstrel's pot-red anaphoric amphora at the end, "barnacled and sea-grown from long voyaging" (Barth 1988: 196). In Barthian terms, there is no known, prescribed way through a labyrinth and no left-to-right progression through the stories, which turns the space into a kind of metanarrative device. Like in the mirror-maze of the title story, the protagonists and perspectives multiply and disappear, but the scenery stays. The funhouse itself might stand for a lot of things: narration, life, or something else entirely.

Barth's protagonists choose directions based on their drives and desires, but in a world as relative and unfathomable as the funhouse, such drives lead nowhere. The nature of reality does not match the motives of the protagonists. The hero is always the one who cannot fathom something: Menelaus, the sperm, Ambrose, they are all flabbergasted by at least one aspect of the world they are surrounded by because they themselves are ambivalent and their choices are arbitrary.

Since Barth does not superimpose the author's power of creation on the reader's potentials of interpretation, this reader's intention has been to interpret the stories based on their landscapes. Space has a different influence on the protagonists, the reader, and the storyteller. As the reflexion of a writer's self-consciousness, space is both a gift and a burden. For the protagonist and the reader, it is often perplexing but for the storyteller, it is a nurturing device, "the world winks at him through its objects" (Barth 1988: 88), his "palate attuned to subtler dishes" (Barth 1956: 116-117). These early 
signs that there is something special about the hero do not point to him as a redeemer but a storyteller. The labyrinth is one of the hero's attempts to domesticate otherness by assuming the role of a storyteller. It is a piece of machinery set to bring the story to life like the night sea does for the sperm or the funhouse of the title story for Ambrose.

\section{References}

Barth, J. (1988). Lost in the Funhouse: fiction for print, tape, live voice. New York: Anchor Books.

Barth, J. (1984). The Friday Book: Essays and Other Non-Fiction. London: The John Hopkins University Press.

Barth, J. (1984). The Literature of Replenishment: Postmodernist Fiction. In: The Friday Book: Essays and Other Nonfiction. London: The John Hopkins University Press, 193-206.

Barth, J. (1956). The Floating Opera. New York: Appleton, Century Crofts, Inc.

Butler, C. (2002). Post-modernism: A Very Short Introduction. Oxford: Oxford University Press.

Lindsay, A. (1995). Death in the Funhouse: John Barth and Poststructuralist Aesthetics. New York: Peter Lang.

Prince, A. (1968). An Interview with John Barth. Prism, Spring 1968, 42-62.

Walkiewicz, E. P. (1986). John Barth. Boston: Twayne Publishers. 